\title{
Warning System Options for Landslide Risk: A Case Study in Upper Austria
}

\author{
Anna Scolobig ${ }^{1, *}$, Monika Riegler ${ }^{2}$, Philipp Preuner ${ }^{2}$, JoAnne Linnerooth-Bayer ${ }^{2}$, \\ David Ottowitz ${ }^{3}$, Stefan Hoyer ${ }^{3}$ and Birgit Jochum ${ }^{3}$ \\ 1 Climate Policy Group, Department of Environmental Systems Science, Swiss Federal Institute of \\ Technology (ETH Zurich), Zurich 8092, Switzerland \\ 2 Risk and Resilience Program, International Institute for Applied Systems Analysis (IIASA), Laxenburg 2361, \\ Austria; riegler.monika@gmail.com (M.R.); preuner@iiasa.ac.at (P.P.); bayer@iiasa.ac.at (J.L.-B.) \\ 3 Department of Geophysics, Geological Survey of Austria (GSA), Vienna 1030, Austria; \\ david.ottowitz@geologie.ac.at (D.O.); stefan.hoyer@geologie.ac.at (S.H.); birgit.jochum@geologie.ac.at (B.J.) \\ * Correspondence: anna.scolobig@usys.ethz.ch; Tel.: +41-446-324-498
}

Received: 19 May 2017; Accepted: 5 August 2017; Published: 11 August 2017

\begin{abstract}
This paper explores warning system options in the landslide-prone community of Gmunden/Gschliefgraben in Upper Austria. It describes stakeholder perspectives on the technical, social, economic, legal and institutional characteristics of a warning system. The perspectives differ on issues such as responsibility allocation in decisions regarding warnings, technologies used for monitoring and forecasting, costs and financial aspects, open data policies and the role of the residents. Drawing on the theory of plural rationality and based on a desk study and interviews, stakeholder perspectives and discourses on the warning system problem and its solution were elicited. The perspectives formed the basis for the specification of three technical policy options for a warning system in Gschliefgraben: a minimal-cost and cost-effective system; a technical-expert system; and a resident-centered system. The case demonstrates the importance of accounting for a plurality of values and preferences and of giving voice to competing discourses in communities contemplating warning systems or other public good policies. This paper concludes that understanding the different and often conflicting perspectives and technical policy options is the starting point for formulating an agreed compromise for an effective warning system. We describe the compromise solution in an accompanying paper included in this Special Issue.
\end{abstract}

Keywords: warning system; landslide risk; technical policy option; stakeholder perspectives; warning communication and decision making

\section{Introduction}

Scientific innovation and technological development have made it possible to include precise information about landslide hazards and the exposure of the population in landslide warning systems [1]. More precisely, the second half of the twentieth century witnessed innovation in the quality, quantity and availability of hazard, risk and weather information and in the provision of state-of-the-art warning and advisory services [2]. Enhanced instruments and technology, including real-time data collection and capability for modeling and dissemination of information, have given rise to warning systems that are increasingly sophisticated.

However, the advancement of technical capabilities has not been matched by a corresponding advancement in the social capabilities for managing a warning system, particularly communicating and improving decision-making regarding warnings (By communication we mean the act of conveying information about the warning from one person/group to another through the use of mutually understood words and rules. By decision making we mean the stakeholder process resulting in the 
selection of an action among several alternative possibilities (e.g., from providing warning messages to evacuation). This is shown, for example, by the accelerating trend in legal conflicts related to the use and interpretation of weather data and by the disconnects between the official information provided by local authorities and residents' responses [3-7]. Indeed, warnings are most effective when the public fully comprehends the risks to life and property, as well as their options for pursuing safety, demonstrating the need for understanding and improving the communication process. Previous research shows that residents living in risky areas should not only be aware of the danger but they should also feel responsible for their safety and behaviors in case of an alert or alarm [8,9]. This can be achieved through effective training, communication and public participation in the decision-making processes to set up a warning system [10-12].

Problematic issues hindering decision-making processes include not only low public participation, preparedness, risk awareness and knowledge but also institutional factors such as lack of resources, inadequate communication protocols, ineffective engagement with the media and the private sector, and lack of clarity surrounding who is responsible for issuing warnings [2,13-18]. There is a vast literature on the barriers to effective warning systems, which include difficulties in reaching target groups and/or addressing their interests and concerns; a lack of clarity and completeness of the information provided; ineffective communication of uncertainty, and the absence of a single voice providing advice, especially in light of the proliferation of communication technologies such as social media $[2,9,13-16,19-21]$.

To date, most of the research addressing the societal aspects of warning systems and emergency management has focused on the risk perceptions, attitudes and behaviors of the public, rather than the institutional, professional and other stakeholders involved in the warning decision-making chain. These include, for example, weather forecasters, media and broadcasters, scientific advisers, private sector meteorologists, public agencies, emergency managers and public officials [20-22].

Research has also tended to focus primarily on issues related to the dissemination of warnings to the public, such as message design and dissemination, psychometric and demographic factors related to warning response, public understanding of probabilistic statements, and effective communication of uncertainty. Few studies have adopted a systemic perspective to better understand the views of institutional and professional stakeholders in addition to the public. For example, disagreements, unclear responsibility allocation, and conflicts or lack of coordination among diverse and heterogeneous stakeholders can generate stalemate in the decision process or contention with regard to the decision outcome (e.g., $[23,24])$. The case of the earthquake that struck the city of L'Aquila and its province in central Italy on 6 April 2009 shows how unclear responsibility allocation can generate serious problems in the decision-making process and outcome. A critical issue concerned the mandate of members of the Italian Major Risk Commission (an advisory body connecting the National Civil Protection and the scientific community), which not only had to provide advice, but also to communicate it to the public. The warning communication process, that is, the way information was conveyed to the local population, was at the center of this case. Indeed, six days after the earthquake hit L'Aquila, the relatives of some of the victims claimed that the injuries and deaths occurred because the victims had failed to enact the usual precautionary measures because of the official reassurance they had received from the authorities, including members of the Italian Major Risk Commission. The case shows that even if the legislation clearly distinguishes the role of scientific advisors from decision makers, responsibility for the provision and communication of scientific information during a warning can be ambiguous $[17,25,26]$.

Another example of unclear responsibility allocation and lack of coordination among stakeholders that led to contention with regard to the decision outcome is the Xynthia storm. Without formal warning, the storm hit the west coast of France in 2010. When the storm burst seawalls in the town of La Faute-sur-mer in the Vendée region, many of those killed were still asleep [18]. Most of the victims were unaware that their homes were built in areas at high risk of flooding. Relatives of the victims 
wanted to know who allowed the homes to be built in such dangerous areas, why the residents had not been appropriately informed about the risk and why no proper flood warnings were issued [17].

As these examples show, it is important to focus attention on the socio-political, institutional and legal context of warning systems, although to date the overriding emphasis has been on their technical and scientific aspects. Scant attention has been paid to how to integrate the different components of warning system options, i.e., the alternatives for their design and implementation [27]. These include technological (e.g., instruments and devices), societal (e.g., public awareness and preparedness, warning communication), economic (e.g., costs) and legal/institutional (e.g., responsibility allocation) components. The choice of these components ultimately reflects views on the key problems and solutions related to the design and implementation of warning systems. Because these views typically differ among the stakeholders, an inclusive process may be called for. Another research gap is the lack of guidance on how to design inclusive processes that involve stakeholders and experts for the purpose of co-producing knowledge for the establishment of warning systems.

This paper addresses selected research gaps described above. The research questions can be synthesized as follows: how do stakeholders conceive the characteristics of warning systems? How do they frame problems and solutions related to their design and implementation? What are the salient differences in stakeholders' frames or perspectives as revealed by their discourses? How can their different or plural perspectives be reconciled for the choice of warning system options?

In this paper, we address these questions by exploring stakeholder perspectives on the technical, social, economic and institutional characteristics of a warning system. The case study is a landslide-prone community in Upper Austria, Gmunden/Gschliefgraben. The following section provides background on the case before describing the research design and conceptual framework (Section 3) and the reasons for the stalemate concerning the decisions about the warning system (Section 4). The core of the paper is formulating stakeholder discourses and translating them into warning system options, which are presented in Section 5. We conclude our discussion in Section 6.

\section{Case Study}

Gschliefgraben is a landslide-prone area, approximately $3 \mathrm{~km}$ long and $1 \mathrm{~km}$ wide, located in the municipality of Gmunden in Upper Austria. Gmunden has around 13,000 inhabitants, and around 100 of them live in and around the landslide-prone area and are directly or indirectly at risk. On the eastern side of the Traunsee in Upper Austria, located between the mountains Traunstein and Grünberg, complex geological preconditions have caused translational slides and earth flows over a long history. Because of favorable climatic conditions for agriculture, Gschliefgraben was settled early on despite recurring devastating mass movement events [28]. Its popularity among residents and tourists today is due largely to its beautiful scenery. The first known disaster destroyed agricultural areas in the mid-15th century [29]. A danger zone plan produced by the Torrent and Avalanche Control (WLV), an Austrian federal authority, has been in force since 1987, prohibiting buildings and new settlements in the risky area, taking into account landslide risks, flood debris accumulation and river excavation.

The most recent landslide disaster in Gschliefgraben occurred in November 2007, when a progressive mass movement took place: approximately 22 ha of surface and in total $4 \times 10^{6} \mathrm{~m}^{3}$ were in motion at the most active time [29]. Around 100 people and 55 buildings had to be evacuated; the last remaining evacuees were allowed to return to their houses after nine months in August 2008. Triggers for this event might have been the high precipitation and long lasting snow cover that drenched the underlying marl [28] and massive rock fall in 2005/2006 and put additional weight on the slope [30]. Immediate actions to stop the mass movement included removing woodland, digging trenches and wells, and positioning pipes for drainage. In addition, the feeding river Lidringgraben was dug out to prevent additional water infiltration. In the longer run, as an addition to these structural measures, efforts were undertaken to stabilize the slope by planting black alder and other deciduous trees [28,30]. After these events, a pre-existing monitoring system (The main focus of a monitoring system is to reach an improved knowledge about the behavior of a certain process-in this case a 
landslide process-by continuous observation of various parameters. The improved knowledge is the basis for the decision making process. In the case of an early warning system the observed monitoring parameter is used in real time (by defining thresholds) as an input for a decision that can range from warning messages to evacuation) was improved by adding an inclinometer and geoelectrics tools (for a definition of these technical measures see Table 1).

Table 1. Technical measures for the landslide warning system in Gschliefgraben.

\begin{tabular}{ll}
\hline Technical Measure & \multicolumn{1}{c}{ Definition } \\
\hline GPS surface monitoring & Monitoring of the surface movement with several GPS receivers placed on the moving landslide. \\
\hline Inclinometer chain & $\begin{array}{l}\text { Several 1 m long segments of chain that include different orientation sensors. The system is installed } \\
\text { into a borehole and measures the displacement related to depth. }\end{array}$ \\
\hline Piezometer & A pressure sensor dedicated to monitoring of the groundwater level in a water filled borehole. \\
\hline Geophones & $\begin{array}{l}\text { Low price seismometers (often used in the oil industry in seismic exploration) that measure the } \\
\text { seismic waves passing the instrument. This can provide information about ongoing rock fall activity. }\end{array}$ \\
\hline Geoelectrics & $\begin{array}{l}\text { A geophysical method to record the electrical resistivity of a certain volume of the subsurface. } \\
\text { The electrical resistivity is dependent on the soil moisture of the subsurface (among other } \\
\text { factors) -long term observations with this method provide information about the hydrodynamic } \\
\text { processes of the landslide body. }\end{array}$ \\
\hline
\end{tabular}

The estimated costs of the stabilization and reconstruction measures (mainly under the responsibility of the WLV) were more than $€ 13$ million, financed by the Austrian Disaster Relief Fund and co-financed by the Federal Province of Upper Austria and the Municipality of Gmunden.

The implementation of an early warning system and emergency plan were considered by WLV to be preconditions for resettlement after a nine-month evacuation period following the last disaster to ensure safety for the local residents [31]. Although a landslide risk mitigation project has been designed by the WLV in 2012, the implementation was postponed because of financial and political issues. Technical measures suggested by WLV include GPS surface monitoring, two inclinometer chains, a piezometer, geophones, groundwater label measures, geoelectrics to measure soil water content, ultrasound measurement of flow rates in drainage pipes (see Table 1). The costs sum to around $€ 500,000$ [31].

Changing political frameworks, as well as different stakeholder conceptions and problem/solution frames, resulted in a long lasting deadlock concerning warning system implementation, which lasted until the beginning of the fieldwork for this research, in September 2015. In the following sections we describe the research design and the reasons for this deadlock (see Sections 3 and 4, respectively).

\section{Research Design}

Our research design can be divided in three main phases: desk study, fieldwork and data analysis.

Table 2 summarizes the research phases and briefly describes the key steps before providing a detailed account in Sections 3.1 and 3.2.

Table 2. Research phases (Key methodological references in brackets).

\begin{tabular}{|c|c|}
\hline Phase & Description \\
\hline Desk study & $\begin{array}{l}\text { Collection of data from different sources including census, municipal archives, regional and municipal policy } \\
\text { documents, legislation and newspaper articles [32] }\end{array}$ \\
\hline \multirow{2}{*}{ Fieldwork } & Participant observation in the municipality of Gmunden [33] \\
\hline & 21 semi-structured interviews based on protocol (Appendix A)/snowball technique to select the sample $[34,35]$ \\
\hline \multirow{5}{*}{ Data analysis } & Identification of the key issues on which stakeholders' views on the warning system differ considerably [34] \\
\hline & $\begin{array}{l}\text { Clustering of key issues, ideas and opinions to construct discourses based on the conceptual framework of plural } \\
\text { rationality theory [36] }\end{array}$ \\
\hline & $\begin{array}{l}\text { Construction of three discourses: (i) a minimal cost system; (ii) a technical expert system; (iii) a resident centered } \\
\text { system }[37,38]\end{array}$ \\
\hline & Design of warning system options informed by each discourse [39] \\
\hline & Use of warning system options in a participatory process (documented in [40]) \\
\hline
\end{tabular}




\subsection{Desk Study and Fieldwork}

As already described in Section 1, in this paper we explore stakeholder perspectives about the technical, social, economic and institutional characteristics of a warning system in Gschliefgraben.

We identified these perspectives by conducting a desk study and fieldwork in the municipality of Gmunden.

For the desk study, we collected data from different sources including census (to collect demographic information), municipal archives (to collect information about the landslide), legislation, newspaper articles (archives from the local newspapers Salzi.at, Tips and OO Nachrichten have been consulted), regional and municipal policy documents e.g., [28-31]. We used these data to build the background for the case study and to better understand the reasons of the deadlock surrounding decisions about the warning system.

Besides collecting data, we conducted extensive fieldwork in the municipality of Gmunden. The research involved several visits to the area affected by the landslide (Gschliefgraben) to gain an understanding of the main characteristics of the existing monitoring, warning and protection systems under the guidance of local technicians. The research team also engaged in informal conversations with civil servants, elected representatives and residents. This first phase of participant observation generated valuable data from stakeholders/interviewees that informed the design of the participatory process (documented in [40]). In addition, this phase proved very useful for establishing links with local authorities and residents.

In the second phase of the fieldwork, 21 face-to-face, semi-structured interviews were carried out. To select the interviewees, we used a snowball sampling technique, i.e., a non-probability technique where existing interviewees recruit future ones from among their networks. The interviewees included representatives of the WLV, the mayor, heads of technical, planning, and environmental departments involved in urban planning and emergency management, experts in geology, civil engineers, scientific researchers, firefighters and civil protection officers, members of voluntary organizations and residents. The interviews were based on a prepared protocol (reproduced in Appendix A). The topics addressed in the interviews can be synthesized as follows: early warning system design and emergency management, responsibility allocation, warning communication, decision-making chain, community preparedness, funding for the warning system and local capacities. Different and often contending stakeholders' views on the problems related to the warning system, and how they should be addressed, emerged clearly during the interviews. This allowed us to identify the issues or concerns on which the stakeholders' views differed: risk awareness, responsibility allocation, costs, funding, technology, emergency planning, resident engagement, communication and transparency. These issues formed the background for constructing the stakeholder discourses, based on the method of discourse analysis and the theory of plural rationality as described in Section 3.2.

Most interviews were audio-recorded, subject to the interviewee's consent. As follow up, the notes were revised and interview tapes transcribed (fully or partially) and submitted to the interviewee before integration with other data and findings (e.g., from participant observation). Each interview lasted about 1-1.5 h. In the following sections (Sections 4 and 5) interview excerpts are identified by the interview number, in order to guarantee the anonymity of the respondents.

\subsection{Data Analysis}

As a first step in the data analysis, we coded the interview data looking for key issues [32,34] (as already described in Section 3.1, these issues are: risk awareness, responsibility allocation, costs, funding, technology, emergency planning, resident engagement, communication and transparency). For example, concerning risk awareness, some interviewees do not consider landslide risk to be a main concern for the community, some are quite concerned about the risk, others are not only concerned but also think that a multi-hazard approach should be adopted for risk management and that residual risk should be taken into account. Concerning responsibility allocation, for some interviewees the municipality should have primary responsibility for the warning system; for others, 
responsibility should be shared between the municipality and the residents; others view the WLV as having responsibility for monitoring and the municipality for maintenance (for a detailed account of opinion clusters see Table 3 and Section 5).

During the analysis it also emerged that the views on some key issues often cluster: for example, those that feel landslides are not their main concern typically delegate responsibility to the municipality. By clustering the key issues, we constructed stakeholder views and "discourses"-i.e., shared, structured ways of speaking, thinking, interpreting, conveying and logically connecting ideas [37]. We used discourse analysis methodology, which provides a situated reading of a certain topic or problem and does not consider any accounts to be true or false descriptions of "reality", but investigates how different ways of describing facts or ideas are produced [37].

The theory of plural rationality (also called cultural theory [36]) served as a heuristic and conceptual framework for discourse analysis. This theory postulates that stakeholder views or rationalities are plural but limited in number. The rationalities stem from different social contexts, which, in turn, are shaped by the ways in which people organize, perceive and justify their social relations. The plural rationality literature refers to contentious problem contexts that require accounting for such plurality as "contested terrains" [41] and, if the problem is also characterized by high stakes and deep uncertainty, as "wicked problems" [42]. According to the theory there are four main rationalities: individualism, hierarchy, egalitarianism and fatalism.

Below we summarize the key characteristics of each rationality as informed by the stakeholder interviews guided by the literature on plural rationality $[28,30]$.

- Stakeholders identifying with the "individualist" perspective value choice, which means, for example, that residents in landslide-risk areas should make informed decisions on where to live and when to evacuate. Information and warnings to inform these choices are necessary; yet, those inclined toward this perspective tend to focus on tradeoffs between costly warning systems and other competing uses of public funds (requiring attention to costs and benefits).

- Consistent with the "hierarchical" perspective, the world is controllable and stable within boundaries, which are established by experts and competent authorities. Stakeholders inclined toward this perspective tend to rely on authorities for warning-related decisions, which they feel can be made most effectively from a top-down approach.

- "Egalitarian" respondents tend to take a critical and moral perspective, and are inclined to view technical fixes-such as warning systems-as the problem and not the solution. It is important to take a holistic approach by focusing on the causes of the landslide risk, on resulting social inequalities and the consequent disruptions to the overall ecological and geomorphological system. Those with this persuasion typically refuse cost-benefit reasoning and value landscape preservation. If a warning system is deemed necessary, they value resident engagement in its design and operation.

- Finally, for "fatalists" nature is unknowable and unpredictable and there are few possibilities to control it, for example, by means of technical devices.

According to the theory, the four rationalities, in varying strengths and often in pairwise alliances, are universal in the sense of appearing in all societies and present at all levels of social organization from the individual to the village, nation state and globe [38,43]. There is growing documentation of discourses reflecting these plural rationalities across policy issues ranging from risk management (e.g., climate risks, landslide risk, seat belts and flood insurance) to public goods and common resource management (e.g., harvesting whales, forest management) and development assistance. e.g., [39,41,44-49].

Our data analysis yielded three main discourses related to warning systems, which reflect the individualist, hierarchical and egalitarian perspectives, respectively: (i) a minimal-cost warning system; (ii) a technical-expert warning system; and (iii) a resident-centered warning system. We found little trace of the fatalist perspective among those stakeholders actively involved in the warning system 
issues, and for this reason we focus only on the remaining three policy active discourses. Section 5 provides a detailed description of the three discourses and of the warning system options informed by each discourse. The options formed the basis of the participatory process organized in Gmunden to reach a compromise on the warning system design and implementation. This process is presented in [40].

\section{The Deadlock Surrounding Decisions about the Warning System: Political, Institutional and Financial Barriers}

Although the installation of a warning system was a precondition for resettlement in the red zone in Gschliefgraben (i.e., the most endangered area in the danger zone plan of Gmunden), there was considerable disagreement among stakeholders, especially residents and authorities, about the form it should take. One of the main problems concerned responsibility for the warning system. The local authorities and WLV claimed to have a good cooperation, but the residents complained about the lack of communication between authorities. A key issue was the responsibility for the maintenance of the existing measures. A resident in Gschliefgraben said: "when I talk with the municipal authorities about landslide risk, I argue that something has to be done to maintain the existing measures. Yet, they assure me that the WLV is informed and will take care of it. However when I ask the WLV, they tell me they are not responsible. They maintain that the municipality is responsible" (A11). In addition, some residents have not signed a subserviency allowing the maintenance workers to enter their land. Such issues impede the ongoing management of the slope, hamper the future elaboration of the warning system and affect the interaction between residents and authorities.

After the 2007 landslide, the municipal officers did not feel competent to decide on the design of a warning system and called for expert advice. However, they "still have no information about what is really necessary for monitoring purposes" according to a representative of the local building authority (A4). Indeed no precise instructions were provided about the specific characteristics of the warning system (considered as a precondition for resettlement in the red zone). The opinions about the necessary technical measures differ substantially between stakeholders (e.g., the province, WLV, civil engineers and scientists).

Moreover, despite the fact that landslides have led to extensive damage in the past (and especially after the 2007 landslide), the risk has not been a political priority in the last decade. Because of the long timespan between the events, early warning and risk management for landslides are of secondary importance for local authorities and are difficult to communicate to the public. As maintained by a geologist: "If the municipality undertakes long-term financial obligations to install an early warning system, they have to strongly argue why this investment is useful for all residents of the municipality and not only the ones in the landslide prone area" (A14). One key question is how to legitimize substantial investment of tax money to cope with a rather small-scale problem concerning only a small percentage of residents (100 out of 15,000$)$. Critical in this regard is the question of how many buildings are actually under threat. After the event in 2007, an officer of WLV maintained "the journalists focused their attention on the few houses in the central part of the slope, and ignored the others which became less threatened due to the remediation measures. (...) Then it was questioned if the spending of public money can be justified with the protection of only 5 to 6 houses" (A2). However, many more buildings than the 5-6 reported by the media were under threat, together with the road to another village south of the red zone (i.e., the most endangered area in the danger zone plan). A resident states: "They didn't do it (remediation measures) only for us, they did it for the whole area!" (A12).

Although the distribution of the costs of an early warning system is clear for all concerned parties (municipality, province and state pay a third each), it is not clear which technological measures are necessary for monitoring. As stated by an officer of the local building authority: "nobody could tell us so far, what is really important, what we have to pay for and what is useful only for scientific purposes" (A4). The municipality is willing to pay for the minimum technical equipment, in order to fulfill the legal standards. In contrast, representatives of state authorities and scientific parties consider an early 
warning system as an opportunity to gain scientific insight: “( . . ) we invested around 15 million Euro to protect this village. Public money! So we expect to collect sound and relevant scientific information." (A9).

Another problem is the uncertain maintenance costs of the warning system. The municipality is facing some financial problems and is therefore not willing to take on these costs. As a result, the possibility of requiring the residents to pay for a share of the costs has been discussed intensely, and a public officer states: "Huge amounts of money derived from the taxes have been spent to stop the slope from moving, especially in Gschliefgraben. Only those who derive benefits from the warning system (and not all tax payers) should pay" (A10). Some interviewees maintain that residents should contribute to the costs of the warning system and see this contribution as an opportunity to increase their sense of agency and to agree on an economically sound option: "People have exorbitant requirements for safety devices if their own property is involved. But when they realize that they have to pay for at least parts of it on their own, their wish list becomes more realistic and do-able. Furthermore, if it is free, it can't be any good: If the people don't know what certain measures cost, they expect that anything feasible will be done for their protection, although it might not be cost-effective" (A10).

At the time fieldwork began for this research, the debate on the political, institutional and financial issues related to the implementation of the warning system was still open.

\section{Stakeholder Perspectives and Warning System Options}

As described in Section 3, we selected seven issues on which stakeholder views differed considerably: i.e., risk awareness (perceived risk), responsibility allocation, costs, funding, technology, emergency planning, resident engagement, communication and transparency. The views clustered into three discourses related to warning systems, which reflect the individualist, hierarchical and egalitarian perspectives, respectively: (i) a minimal-cost warning system; (ii) a technical-expert warning system; and (iii) a resident-centered warning system. Before describing in detail each discourse, Table 3 provides an overview, including how the discourses relate to the seven warning system issues.

Table 4 describes how different groups of interviewees cluster around the three discourses (in percentage of interviewees). To maintain the anonymity of the interviewees, we divided them into three main groups: residents (those most directly exposed to landslide risk), administrators (local politicians and those who work in the public offices without specific technical knowledge of warning systems), technicians (those in charge of technical evaluations to assist administrators). The table was prepared by the authors based on the interview results. It is interesting to note that a greater percentage of administrators than residents embrace the "resident centered" warning system discourse. The highest percentage of residents (20\%) embraces the discourse on the "technical" warning system. This may seem contradictory at first sight but shows that residents tend to favor delegating responsibility for the warning/protection to the experts and the local authorities (for a better explanation see [40]). The opposite is true for the "technical" warning system discourse: a low percentage of administrators $(5 \%)$ engage in this discourse in comparison with the relatively high percentage of residents $(20 \%)$ and technicians $(20 \%)$.

The following sections will describe the three discourses in more depth and construct potential warning system options informed by the discourses. 
Table 3. Stakeholder views on warning system issues grouped by discourses.

\begin{tabular}{|c|c|c|c|}
\hline Key Issue & Minimal-Cost Warning System & Technical-Expert Warning System & Resident-Centered Warning System \\
\hline Risk awareness & $\begin{array}{l}\text { Landslide risk is exaggerated, and is not } \\
\text { the main concern for the community }\end{array}$ & $\begin{array}{l}\text { With mitigation measures, residual risks are low, } \\
\text { but it is important to provide safety even for } \\
\text { low risks }\end{array}$ & $\begin{array}{l}\text { Residual risks are low but unacceptable especially } \\
\text { if they affect vulnerable families in the community }\end{array}$ \\
\hline Responsibility allocation & $\begin{array}{l}\text { Individual households can decide on } \\
\text { evacuation; yet municipality should } \\
\text { have responsibility for warning }\end{array}$ & $\begin{array}{l}\text { The relevant authorities should have } \\
\text { responsibility, in this case the WLV for monitoring } \\
\text { and the municipality for maintenance }\end{array}$ & $\begin{array}{l}\text { Local awareness and involvement is desired, } \\
\text { meaning the municipality and residents should } \\
\text { have main responsibility }\end{array}$ \\
\hline Cost & $\begin{array}{l}\text { Since risk is low, costs should be kept to } \\
\text { a minimum }\end{array}$ & $\begin{array}{l}\text { Safety must be assured by the authorities, so } \\
\text { required costs should be allocated to monitor the } \\
\text { slope in the long term and minimize residual risk }\end{array}$ & $\begin{array}{l}\text { Unacceptable residual risk means costs should be } \\
\text { allocated to monitor the slope in the long term } \\
\text { and minimize residual risk }\end{array}$ \\
\hline Funding & $\begin{array}{l}\text { Since those benefitting are local, the } \\
\text { municipality should bear the costs and to } \\
\text { a lesser extent the region and state }\end{array}$ & $\begin{array}{l}\text { Costs should necessarily be allocated to the } \\
\text { municipality, regional, and state authorities, but } \\
\text { affected residents can also contribute }\end{array}$ & $\begin{array}{l}\text { Since responsibility lies with the local authorities } \\
\text { and the residents, they should share the costs }\end{array}$ \\
\hline Technology & $\begin{array}{l}\text { There is no need for new and expensive } \\
\text { technology; maintenance and inspection } \\
\text { of existing measures is sufficient }\end{array}$ & $\begin{array}{l}\text { A combination of various monitoring technology } \\
\text { is necessary to ensure effective measures and to } \\
\text { guarantee the greatest possible degree of safety }\end{array}$ & $\begin{array}{l}\text { Local control means that data transparency is } \\
\text { essential, and technologies should provide } \\
\text { information to residents; there is less need for } \\
\text { technologies that feed scientific understanding }\end{array}$ \\
\hline Emergency planning & $\begin{array}{l}\text { Extensive emergency planning is not } \\
\text { necessary because risk is low. Excessive } \\
\text { attention to this issue may intimidate } \\
\text { residents and lower property values }\end{array}$ & $\begin{array}{l}\text { Emergency planning is all important, also to } \\
\text { clarify responsibilities of stakeholders }\end{array}$ & $\begin{array}{l}\text { Emergency planning is a central aspect for } \\
\text { effective warning systems, and it should include } \\
\text { documentation and legal procedures }\end{array}$ \\
\hline Residents engagement & $\begin{array}{l}\text { There is no need for extensive and costly } \\
\text { engagement of residents }\end{array}$ & $\begin{array}{l}\text { Residents should have a minor role, but active } \\
\text { engagement, especially if combined with financial } \\
\text { responsibility, is useful }\end{array}$ & $\begin{array}{l}\text { Residents should have an active role with } \\
\text { co-responsibility for the warning system }\end{array}$ \\
\hline Communication and transparency & $\begin{array}{l}\text { For a minor issue, no need for } \\
\text { information events }\end{array}$ & $\begin{array}{l}\text { Information events are important for an } \\
\text { expert-driven system; priority should be on } \\
\text { data security }\end{array}$ & $\begin{array}{l}\text { To fully involve residents, there should be regular } \\
\text { information events, training courses and } \\
\text { data sharing }\end{array}$ \\
\hline
\end{tabular}


Table 4. Interviewee clusters around the discourses (in percent of interviewees).

\begin{tabular}{cccc}
\hline Interviewee & $\begin{array}{c}\text { Minimal Cost Warning } \\
\text { System }\end{array}$ & $\begin{array}{c}\text { Technical Warning } \\
\text { System }\end{array}$ & $\begin{array}{c}\text { Resident Centred } \\
\text { Warning System }\end{array}$ \\
\hline Residents & 0 & 20 & 10 \\
Administrators & 10 & 5 & 15 \\
Technicians & 0 & 20 & 20 \\
\hline
\end{tabular}

\subsection{A Minimal Cost Warning System}

This discourse emphasizes the importance of rational and informed choice and the right of citizens to decide on their preferred warning system, along with the importance of considering the costs of the proposed technologies/instruments in relation to their social benefits. It reflects the individualistic view in plural rationality theory.

Interviewees embracing this discourse expressed concern that the seriousness of landslide risk is exaggerated, especially given that only a small number of homes may be threatened, and it might be more effective to invest scarce municipal resources in other activities. "When people heard that there are 5, 10, 30 million to be spent, they started to question it. They could not understand why everyone has to contribute considering that 95\% of the population lives on the other side of the lake." (A14) Tradeoffs are also a hallmark of this discourse, especially the tradeoffs between investment in the warning system and other uses of the funds that would promote community welfare. Consequently, interviewees felt that cost-benefit analysis should be the guiding methodology to take these decisions. The discourse can be paraphrased as follows:

Landslides are just one concern among many that residents in Gschliefgraben face in their daily lives. The potential landslide threat is entwined with more immediate higher priority competing demands of everyday life. Implementing an early warning system is more important than maintaining existing remediation measures, which are very costly and paid for with tax money. "The water outflows are often blocked. Maintenance is critical and urgently needed." (A13). At present, the slope is stable but if the structural measures are revoked, the slope might start to move again. Indeed, landslides are very slow processes which can be sufficiently monitored using low cost techniques (e.g., regular site inspection by experts). Expensive new measuring technology with automatic data transfer and a new emergency plan are not necessary to manage landslide risk in Gschliefgraben, because of the small risk and the in-depth knowledge of the subsurface processes that exists. As stated by a local expert: "The last time it happened we saw it coming by merely observing the system. (...) The remediation measures need to be maintained, rather than installing more technology." (A13) A colleague also maintained: "Based on my expertise, I am convinced that the slope is not endangered. An emergency plan is barely necessary." (A14). Furthermore, the implementation of a complex monitoring system and an emergency plan would unnecessarily intimidate residents, lead to a loss of property values and potentially harm tourism in the region. Therefore, preventive risk communication would even be disadvantageous. In the unlikely case of a landslide that lasts for several days and may damage property, there is ample time for residents to protect themselves. Public meetings to inform residents of hazard events are sufficient. Emergency management will include context-specific and individual decisions about the houses affected, the same as in 2007. Finally, the need for new technologies and social media for risk management is negligible.

This discourse can be translated into a warning system option (designed by the authors based on interviews and workshop discussions) characterized by two key elements: (i) monitoring, i.e., the institutionalization of regular inspection rounds and (ii) maintenance of the already existing remediation measures. The key actors involved are: a monitoring committee-in charge of monitoring the changes on the slope such as rock fall, crevices and changes in the vegetation; a relief unit-in charge of emergency management; and an action committee-in charge of deciding on the necessary measures for monitoring, remediation and action in case of an emergency (Figure 1). Finally, the costs 
of this option are very low and new investment is not necessary: personnel and maintenance costs are the main expenses in the budget.

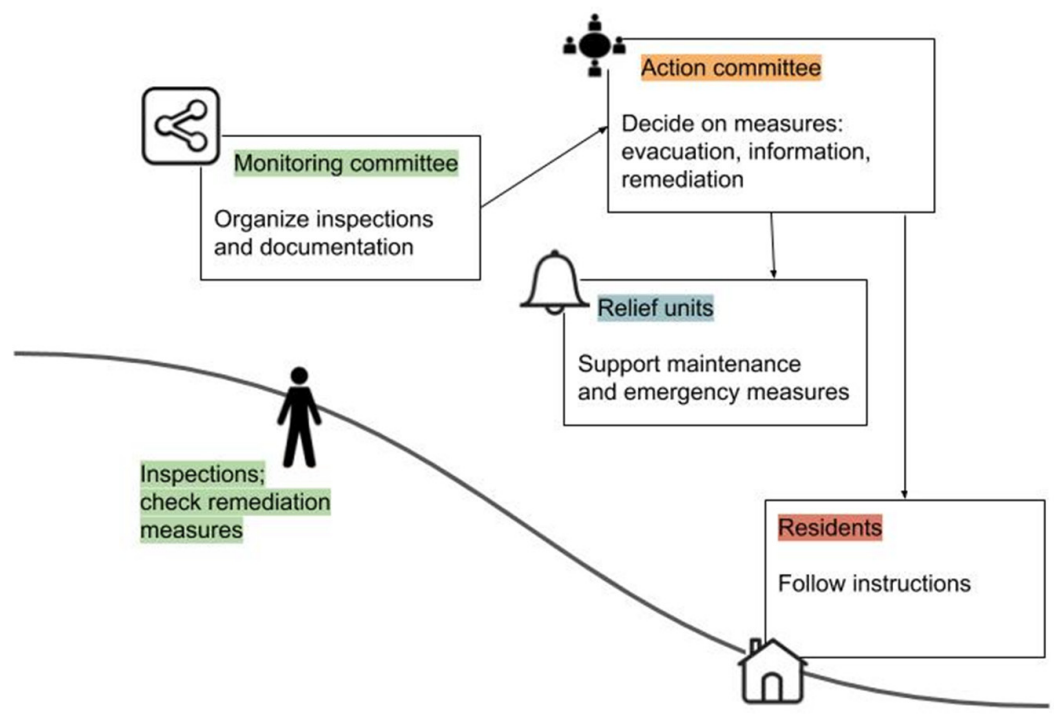

Figure 1. Option 1: A minimal and cost-effective warning system.

\subsection{A Technical Expert Warning System}

This hierarchical and expert driven discourse is characterized by trust in government and expert knowledge. Interviewees embracing this discourse maintain that expertly planned solutions are necessary to set up a warning system. This translates into top-down planning through government authorities with their network of experts. It also translates into a costly technical system to ensure the highest possible level of safety. The discourse can be paraphrased as follows:

Because of structural measures the risk of landslides has decreased. Still, there are residual risks and existing buildings in high-risk areas should be safeguarded.

As maintained by a local expert: "The early warning system should be conceptualized as a multi-level expert system with defined thresholds. (... It is not only the province and federal government that have to pay, but also the affected community." (A2). Moreover, to ensure safety for local residents a technical monitoring and early warning system is required. In addition to existing measures an emergency plan and new fully automatic measuring tools should be installed. This plan should also cover the distribution of responsibilities, the communication and decision making chain in case of emergency and furthermore, contact details of relevant individuals. The early warning system should be conceptualized as a multi-level expert system with defined thresholds. An automatic alert at the Regional Hazard Warning Center should inform the WLV, civil engineering office and municipal authorities when the threshold is exceeded. Afterwards, the experts should discuss and assess the situation on site and decide on the next steps according to the emergency plan. The municipality, province and state should provide funding for the early warning system.

Channels of communication with those affected are mainly information events held by the action committee if the emergency lasts for several days. New technologies and social media are considered to be risky for communication purposes because of the limited accessibility, data protection, and lack of control on information dissemination. The communication of wrong or misleading messages online is considered a major threat to the development of effective warning systems. "I am very skeptical about the on-line publication of data/information about the landslide. Several aspects have to be taken into account because these data can generate useless fear among the residents" (A7).

This discourse can be translated into a warning system option characterized by the following technical aspects: an inclinometer above the main drainage and one below, geophones for rock fall, 
piezometer, measurement of the groundwater table, terrestrial land surveys and a weather station (Figure 2). Under this option, the action committee plays a central role: led by the mayor, this committee should coordinate the alarm/evacuation and take care of the maintenance of technical measures with the support of the relief units. Experts act as key advisors to the action committee. Finally, this option is the most expensive of the three: it requires an investment of about $€ 200,000$ and maintenance costs are also expected to be high. Personnel costs will be slightly higher than for the other options because of the need to include personnel in charge of maintaining the new instruments and technical measures.

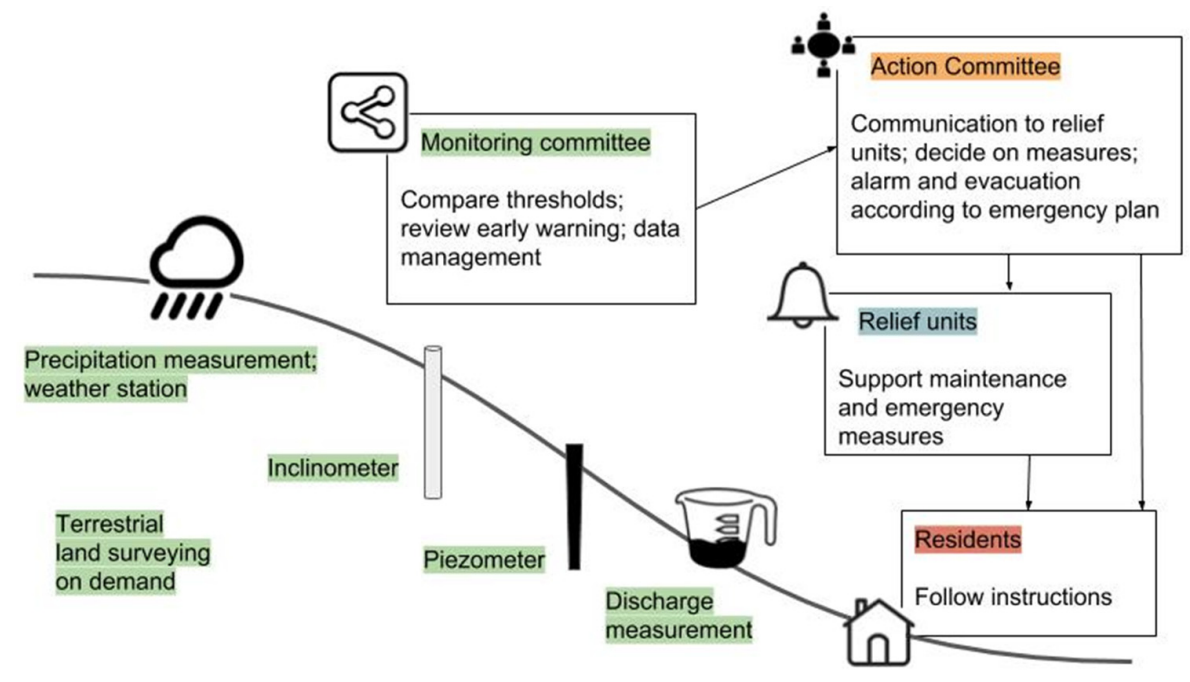

Figure 2. Option 2: A technical expert system.

\subsection{A Resident-Centered and Integrated Warning System}

This discourse is dominated by elements of the egalitarian rationality and, as such, is deeply skeptical of both the individualist notion of tradeoffs and the hierarchical claim that experts know what is best for protection against landslides. This voice argues for a multi-risk, holistic and natural approach to risk management. Egalitarian stakeholders tend to see highly technical systems as the problem and not the solution. Their discourse can be paraphrased as follows:

It is important to minimize landslide risks, especially as they impact the most vulnerable in our communities. As long as existing measures work properly there is only a small risk of landslides in the study area but landslides cannot be ruled out entirely.

The upper part of the slope is still moving and it can influence the low-lying areas. Erosion and lack of maintenance of existing mitigation measures may cause the situation to worsen in the future. In dealing with natural hazards an integrated/multi-risk approach should be adopted. The monitoring system and emergency plan should include debris flows and rock falls, which can be greater threats to the settlement area than landslides.

It is very important that the residents are involved in the design and implementation of these systems, especially since they often have a very good understanding of the mountain and its risks. They should be included in the systems' development, implementation, maintenance, and feel responsible for it. "They can even contribute with direct observations of the landslide" (A6). As maintained by a resident: "The warning system belongs to us and makes us safer." (A3).

Moreover, there should be one person responsible for the early warning system in the municipality. This person should have professional expertise in landslide risk management: "There should be a person responsible for controlling how the warning system works. For example, if there's no power the person should get a notification, go on the site and fix the problem" (A3).

Information transparency and data sharing are key to develop an effective warning system, social media and new technology can play a vital role for risk management. Collected data should be 
accessible for all interested parties including experts, scientists, authorities and residents through internet platforms.

The technical measures necessary for a better understanding of the slope are the inclinometers. Other measures (such as geophones or piezometers) would enable experts to better interpret the system and increase the lead time, but are not strictly necessary. Thresholds have to be clearly defined for the automatic alert to function. Furthermore, responsibilities and duties in case of emergency should be clarified in the emergency plan: "If you start discussing who is responsible for what after the landslide has occurred, it doesn't work" (A8).

This discourse can be translated into a warning system option characterized by the following technical aspects: monitoring of existing remediation measures and runoff; regular inspections including qualitative assessment of drainage discharge; one inclinometer, "geotrail" with information boards distributed on site; and open data communication that includes the wider public (Figure 3). This warning system option is people-centered and residents' preparedness and awareness is one of its critical components. Finally, the estimated cost for this option is about $€ 100,000$. Personnel for the regular inspections mentioned above are another expense to add to the budget. However, maintenance costs are lower than in option 2.

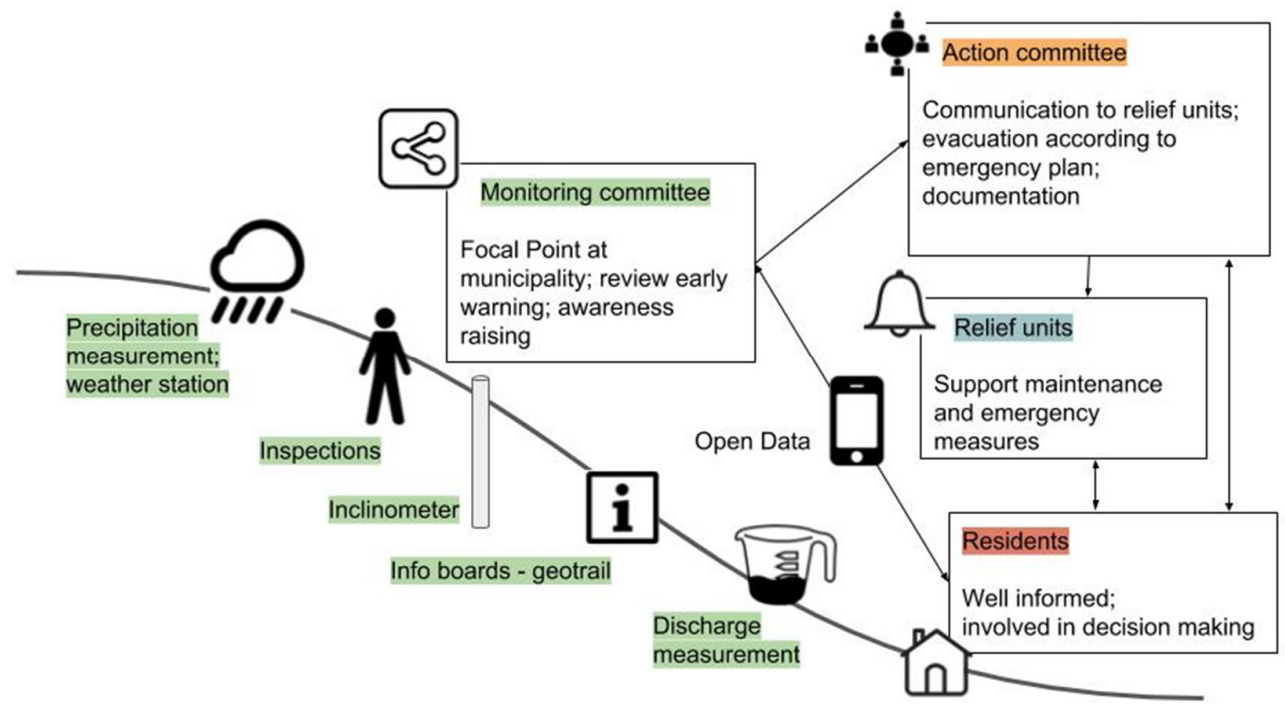

Figure 3. Option 3: A resident centered and integrated warning system.

\section{Discussion and Conclusions}

In this paper, we focused on the design of the warning system for the landslide-prone community of Gmunden in Upper Austria. After an event in 2007, political, institutional and financial barriers contributed in generating a deadlock surrounding the decisions about the warning system. Although the installation of a warning system was a precondition for resettlement in the most endangered area of the town, there was considerable disagreement among stakeholders, especially residents and authorities, about the form it should take. This formed what has been called a contested terrain, where the most argumentative issues concerned responsibility for the warning system, the maintenance of the technical measures for the monitoring, the long-term financial obligations linked to the installation of a warning system and the lack of communication between residents and authorities. In order to address these issues, our research explored stakeholder perspectives and discourses concerning the technical, social, economic and institutional characteristics of a warning system. Working with technical experts, we translated these discourses into three distinct options for the design and implementation of the warning system (a minimal-cost, a technical-expert and a resident-centered warning system), each with its strengths and weaknesses. For example, the "minimal-cost" option does not require expensive technical equipment, and maintenance costs are quite low. In contrast, the "technical-expert" option 
is expensive to install and has high maintenance costs. However, sophisticated data processing and communication mechanisms are necessary and technical failures can cause serious problems. Among its strengths, this option guarantees a high level of security and a long lead time for a warning. The "resident-centered" option is different from the other two because it strongly promotes initiatives to increase community preparedness, such as emergency simulations and communication campaigns as well as a multi-risk approach. Public participation in the decision-making process for the design and installation of the warning system, information transparency and data sharing are also central characteristics of this option.

A characteristic differentiating the options is the ownership of the warning system and the related concept of responsibility: while local authorities and experts are the main players in the "minimal-cost" and "technical-expert" options, residents are involved in the design and implementation of the warning system in the third option. This characteristic proved crucial in the subsequent stakeholder deliberations: discussions became particularly heated concerning the share of responsibilities and costs between residents and local authorities. Finding the most appropriate legal and institutional framework for responsibility sharing (e.g., through the foundation of a resident association to guarantee the functioning and maintenance of the warning system) became the pivotal issue in reaching a compromise solution (see also [40]).

The results of this analysis, in particular the co-generation of multiple stakeholder-based warning system options, are relevant beyond the case of Gmunden. While the implementation of a disaster warning system is typically carried out by public authorities with their network of technical experts, this research shows that the policy questions surrounding the design of a warning system can reach beyond that of a routine technical issue to a complex policy issue characterized by conflicting stakeholder values and preferences, what has been called a "contested terrain". As the stalemate in Gmunden showed, political, social, institutional and economic aspects can play decisive roles in framing the landslide risk policy problem and negotiating its solution. As such, this discussion shows the importance of early-on stakeholder involvement in the technical design of a warning system and its implementation.

This research served as the basis for subsequent stakeholder deliberations by delineating three distinct technical and procedural options for a warning system. The unique quality of these options is that they correspond to the preferences of stakeholders as clustered by their narratives on the problem and solutions. A further message from this paper is that a stakeholder process need not be based on a "best" technical solution, but stakeholder-based options can be produced for subsequent deliberations.

The underlying premise of this research is that stakeholder preferences are formed not only by narrow (usually economic) interests, but are shaped by social context. According to the theory of plural rationality, the diversity of values or preferences is not without structure and can often be clustered into "active" perspectives that may be called individualistic, hierarchical and egalitarian worldviews. The Gmunden case, which built on growing scientific evidence of these plural perspectives in policy debates, demonstrates the applicability of plural rationality theory to identifying contending discourses on establishing a warning system. Theorists of plural rationality claim that the perspectives are universal, which means the three active rationalities may be identifiable in other communities facing landslide or other contested policy issues. While the rationalities (and their combination) are arguably transferable from this and other similar case documentations, the corresponding discourses would likely differ depending on the issue context.

The most important contribution of this discussion and the accompanying paper on the ensuing participatory process [40] is the evidence they add to the hypothesis that understanding and resolving the governance challenges associated with many common goods, in this case a contested disaster warning system, requires accounting for a plurality of values and preferences. The Gmunden case demonstrates, along with a growing literature, the importance of acknowledging and giving voice to competing discourses in communities contemplating warning systems or other public good policies. Co-producing technical policy options was the starting point for the participatory process, which led to 
an agreed compromise solution to the warning system and demonstrated the feasibility of combining expert knowledge with stakeholder perspectives to resolve complex policy issues.

Acknowledgments: The work described in this publication was supported by the Austrian Academy of Sciences International Research Program through the grant to the budget of the LAMOND Project. The paper reflects the authors' views and not those of the Austrian Academy of Sciences. Any member of the LAMOND Consortium is liable for any use of the information in this paper. We thank the stakeholders in Gmunden/Gschliefgraben who devoted their precious time to the interviews. We also profoundly thank the two anonymous reviewers for their precious comments which helped us to improve consistently the quality of the text. Last but certainly not least, we thank Daisy Brickhill (International Institute for Applied Systems Analysis, Vienna, Austria) for her English proof-reading.

Author Contributions: All authors conceived and designed the research. Monika Riegler, Philipp Preuner, David Ottowitz, Birgit Jochum and Stefan Hoyer conducted the fieldwork. Monika Riegler, Philipp Preuner, Anna Scolobig and JoAnne Linnerooth-Bayer analyzed the data. Anna Scolobig with contribution of all co-authors wrote the paper.

Conflicts of Interest: The authors declare no conflict of interest.

\section{Appendix A. Interview Protocol}

\section{Brief introduction about LAMOND project and aims of our WP and of this round of interviews:}

These interviews and the following stakeholder procedures aim at developing an end-user focused warning system by elicitation of stakeholders' perspectives and local discourses. The goal is to gain a better understanding of different perspectives about warning systems, present and future problems, solutions, responsibilities etc. to generate options for the warning system.

\section{Scope of the Interviews:}

In this interview we will deal with landslide risks in Gschliefgraben, warning system and emergency management and their implementation, further we will talk about responsibilities in risk management and the communication chain in risk management (communication between different authorities, experts etc. but also communication of risks to the local residents). Other topics will be funding of risk management and capacities and in a last step we will talk about community preparedness for landslides and responsibility allocation.

Note: The questions below have been asked to all interviewees (see Section 3 of the paper). Depending on their expertise, interviewees provided more or less detailed answers.

\section{Interview Questions:}

\section{Landslide risk}

- In your opinion, how serious is the landslide risk in Gschliefgraben? With what would you compare it? Is it getting worse? Why?

\section{Early warning system}

- How would you define/describe a landslide warning system?

- What are the key characteristics/main pillars? What are the strengths and weaknesses?

- What needs to be done? Who should do it? Who should pay for it?

- What are the opportunities, and what stands in the way of managing the warning system?

- What do you feel are the major unresolved issues?

- Do you think that the present warning system is end user oriented? Why?

- How do you/your organisation deal with the scientific (but also legal and social) uncertainty related to the warning system? (if appropriate)

- Are there local conflicts related to decisions about warning systems?

\section{Emergency management}


- Is there an emergency plan? What do you think are the strengths and weaknesses of the plan? Please provide examples, possibly based on recent experience of emergency management.

- What kind of information is needed for efficient emergency management? Who should have access to this information? How should this information be handled?

\section{Responsibilities}

- Who is responsible for warning system and emergency management?

- Do you think that the present allocation of responsibility is working well? More precisely: do you think that the communication chain between meteorologist/forecast experts, scientific advisors, civil protection officers, fire brigades, the mayor and residents is functional? Please provide examples, possibly based on recent experience of emergency management.

- Is it clear who is responsible for what?

- Should responsibility be reallocated? How?

- On what administrative level should/can an early warning system be embedded? Who should be responsible for planning and maintaining an early warning system?

\section{Capacities and funding}

- Does the local administration have the capacity to deal with emergencies? How could this capacity be improved? Do you think that the funding for emergency management is enough? What have been the priorities in the past and what will be the priorities for the future? Why? What are your views on the support received from regional and national levels for risk identification, communication and management? Is it adequate? If not then what more needs to be done?

- How is communication and interaction organized between organizations from different regional and national levels? Is it adequate? If not, how could information exchange be improved?

\section{Community preparedness}

- What can be the role of citizens/local residents? Do you think that citizens are well prepared? How could they be better prepared? At what point should they be informed in case of emergency?

- What might be suitable channels of communication to do so in your case? What is the role played by new technologies and social media in emergency management? Is it changing? How is it changing?

\section{7 landslide event-how did the warning system work}

- What were people doing when the warning was issued?

- When was an evacuation order given, and what were people doing at that time? Do you think the evacuation order was adequate?

- What were people doing when the landslide hit?

- Who were they with (group context)?

- What actions did they take to avoid the landslide or reach a safe place? Why were specific actions taken (where did they learn to do what they did)?

- What were the most common warning modes? Which seemed to be most effective?

- Did people respond more frequently to warnings by city officials, or by people they knew personally?

- Did people ignore warnings that were heard? Why?

- Why did people not hear warnings?

- How did the systems actually perform in comparison to anticipated effectiveness?

Future-how is the new warning system expected to work 
- What information would you like to receive in case of a warning?

- Who do you think should be in charge of giving this information?

- What do you think might be the best tool to issue a warning?

- Where would you go in case of a warning?

- Whom would you release upon in case of a warning?

- Are you aware of the existence of an emergency plan?

- If yes, do you know who is in charge of preparing it?

- Do you know which the most dangerous areas in Gschliefgraben are?

\section{References}

1. Aitsi-Selmi, A.; Murray, V.; Wannous, C.; Dickinson, C.; Johnston, D.; Kawasaki, A.; Stevance, A.-S.; Yeung, T. Reflections on a science and technology agenda for 21 st century disaster risk reduction. Int. J. Disaster Risk Sci. 2016, 7, 1-29. [CrossRef]

2. United Nations International Strategy for Disaster Reduction (UNISDR). Global Survey of Warning Systems: An Assessment of Capacities, Gaps and Opportunities towards Building a Comprehensive Global Early Warning System for All Natural Hazards; United Nations International Strategy for Disaster Reduction: Geneva, Switzerland, 2012.

3. Cedervall Lauta, K. Disaster Law; Routledge: New York, NY, USA, 2015.

4. Francesco, D.A. La Protezione Civile Nella Societa'del Rischio. Procedure, Garanzie, Responsabilita'; ETS: Pisa, Italy, 2014.

5. Bretton, R.J.; Gottsmann, J.; Aspinall, W.P.; Christie, R. Implications of legal scrutiny processes (including the l'aquila trial and other recent court cases) for future volcanic risk governance. J. Appl. Volcanol. 2015, 4, 18. [CrossRef]

6. Altamura, M.; Ferraris, L.; Miozzo, D.; Musso, L.; Siccardi, F. The legal status of uncertainty. Nat. Hazards Earth Syst. Sci. 2011, 11, 797-806. [CrossRef]

7. Del Carmen Llasat, M.; Siccardi, F. A reflection about the social and technological aspects in flood risk management-The case of the italian civil protection. Nat. Hazards Earth Syst. Sci. 2010, 10, 109-119. [CrossRef]

8. Alexander, D. Emergency command systems and major earthquake disasters. JSEE-J. Seismol. Earthq. Eng. 2008, 10, 137-146.

9. Basher, R. Global early warning systems for natural hazards: Systematic and people-centred. Phil. Trans. R. Soc. 2006, 364, 2167-2182. [CrossRef] [PubMed]

10. Fischhoff, B. Risk perception and communication unplugged: Twenty years of process. Risk Anal. 1995, 15, 137-145. [CrossRef] [PubMed]

11. Kasperson, R. Four questions for risk communication. J. Risk Res. 2014, 17, 1233-1239. [CrossRef]

12. National Research Council. Public Participation in Environmental Decision Making; National Academic Press: Washington, DC, USA, 2008.

13. Handmer, J.; Dovers, S. Handbook of Disaster and Emergency Policies and Institutions; Earthscan: London, UK, 2007.

14. Parker, D.; Fordham, M. An evaluation of flood forecasting, warning and response systems in the european union. Water Resour. Manag. 1996, 10, 279-302. [CrossRef]

15. Parker, D. Criteria for evaluating the condition of a tropical cyclone warning system. Disasters 1999, 23, 193-216. [CrossRef] [PubMed]

16. Parker, D.J. Designing flood forecasting, warning and response systems from a societal perspective. Meteorol. Z. 2004, 13, 5-11. [CrossRef]

17. Scolobig, A. Brief communication: The dark side of risk and crisis communication: Legal conflicts and responsibility allocation. Nat. Hazards Earth Syst. Sci. 2015, 15, 1449-1456. [CrossRef]

18. United Nations International Strategy for Disaster Reduction (UNISDR). Global Risk Assessment Report; United Nations International Strategy for Disaster Reduction: Geneva, Switzerland, 2015.

19. Parker, S.S.; Waldron, H. Dramatically improving warning services-One office's experience. In Proceedings of the 21st Conference on Severe Local Storms, San Antonio, TX, USA, 11-16 August 2002; pp. 413-414. 
20. Parker, D.J.; Priest, S.J.; Tapsell, S.M. Understanding and enhancing the public's behavioural response to flood warning information. Meteorol. Appl. 2009, 16, 103-114. [CrossRef]

21. Sharma, U.; Patt, A. Disaster warning response: The effects of different types of personal experience. Nat. Hazards 2012, 60, 409-423. [CrossRef]

22. Morss, R.E.; Mulder, K.J.; Lazo, J.K.; Demuth, J.L. How do people perceive, understand, and anticipate responding to flash flood risks and warnings? Results from a public survey in boulder, colorado, USA. J. Hydrol. 2016, 541, 649-664. [CrossRef]

23. Morss, R.E.; Demuth, J.L.; Bostrom, A.; Lazo, J.K.; Lazrus, H. Flash flood risks and warning decisions: A mental models study of forecasters, public officials, and media broadcasters in boulder, colorado. Risk Anal. 2015, 35, 2009-2028. [CrossRef] [PubMed]

24. Lazrus, H.; Morss, R.E.; Demuth, J.L.; Lazo, J.K.; Bostrom, A. “Know what to do if you encounter a flash flood": Mental models analysis for improving flash flood risk communication and public decision making. Risk Anal. 2016, 36, 411-427. [CrossRef] [PubMed]

25. Ropeik, D. The l'aquila Verdict: A Judgment Not Against Science, But Against a Failure of Science Communication. Sci. Am. 2012. Available online: http://blogs.scientificamerican.com/guest-blog/2012/10/ 22/the-laquila-verdict-a-judgment-not-against-science-but-against-a-failure-of-science-communication / (accessed on 08 August 2017).

26. De Marchi, B. Scientific advice and the case of the l'aquila earthquake. Technikfolgenabschätzung-Theor. Prax. 2014, 3, 90-94.

27. Priest, S.J.; Parker, D.J.; Hurford, A.P.; Walker, J.; Evans, K. Assessing options for the development of surface water flood warning in england and wales. J. Environ. Manag. 2011, 92, 3038-3048. [CrossRef] [PubMed]

28. Gasperl, W. Katastrophenbewältigung und maßnahmen im gschliefgraben (gmunden/oberoesterreich). In Öaw-Gschliefgraben-Symposium 2009-Proceedings; Weidinger, J.T., Köck, G., Eds.; Verlag der Österreichischen Akademie der Wissenschaften: Wien, Austria, 2010.

29. Weidinger, J.T. Das Gschliefgraben-Rutschgebiet am Traunsee-Osterufer (Gmunden/ooe)—Ein Jahrtausende Altes Spannungsfeld Zwischen Mensch Und Natur; Weidinger, J.T., Köck, G., Eds.; Verlag der Österreichischen Akademie der Wissenschaften: Wien, Austria, 2010.

30. Moser, G. Großhangbewegung Gschliefgraben -Fachübergreifender Synthese-bericht; Weidinger, J.T., Köck, G., Eds.; Verlag der Österreichischen Akademie der Wissenschaften: Wien, Austria, 2010.

31. Wildbach- und Lawinenverbauung (WLV). Gschliefgraben Monitoring; WLV: Wien, Austria, 2012.

32. Yin, R. Case Study Research: Design and Methods; Sage: Beverly Hills, CA, USA, 1994.

33. Glaser, B.G.; Strauss, A.L. The Discovery of Grounded Theory; Aldine de Gruyter: New York, NY, USA, 1967.

34. Silverman, D. Doing Qualitative Research, 4th ed.; Sage: London, UK, 2013.

35. Biernacki, P.; Waldorf, D. Snowball sampling: Problems and techniques of chain referral sampling. Sociol. Methods Res. 1981, 10, 141-163. [CrossRef]

36. Thompson, M.; Ellis, R.; Wildavsky, A. Cultural Theory; Westview Press: Boulder, CO, USA, 1990.

37. Dryzek, J. Environmental Discourses; Oxford University Press: New York, NY, USA, 1997.

38. Thompson, M.; Rayner, S. Risk and governance part 1: The discourses of climate change. Gov. Oppos. 1998, 33, 139-166. [CrossRef]

39. Linnerooth-Bayer, J.; Scolobig, A.; Ferlisi, S.; Cascini, L.; Thompson, M. Expert engagement in participatory processes: Translating stakeholder discourses into policy options. Nat. Hazards 2016, 81, 69-88. [CrossRef]

40. Preuner, P.; Scolobig, A.; Linnerooth Bayer, J.; Jochum, B.; Hoyer, S.; Ottowitz, D.; Riegler, M. Responsibility sharing for landslide warning system: An austrian case study. Resources 2017. (to be submitted).

41. Verweij, M.; Thompson, M. Clumsy Solutions for a Complex World: Governance, Politics, and Plural Perceptions; Palgrave Macmillan: New York, NY, USA, 2006.

42. Churchman, C. Guest editorial: Wicked problems. Manag. Sci. 1967, 14, 141-142.

43. Thompson, M. Wicked environmental problems. In The Companion to Environmental Studies; Hulme, M., Ed.; Cambridge University Press: Cambridge, UK, 2017.

44. Ney, S.; Thompson, M. Cultural discourses in the global climate change debate. In Society, Behaviour and Climate Change Mitigation; Eberhard, J., Sathaye, J., Bouille, S., Eds.; Kluwer Academic Publishers: Dordrecht, The Netherlands, 1999.

45. Thompson, M. Organizing and Disorganizing: A Dynamic and Non-Linear Theory of Institutional Emergence and Its Implications; Triarchy Press: London, UK, 2008. 
46. Scolobig, A.; Thompson, M.; Linnerooth-Bayer, J. Compromise not consensus: Designing a participatory process for landslide risk mitigation. Nat. Hazards 2016, 81, 45-68. [CrossRef]

47. Gyawali, D.; Thompson, M.; Verweij, M. Aid, Technology and Development: The Lessons from Nepal; Eathscan Routledge: London, UK, 2017.

48. Singleton, B. Clumsiness and elegance in environmental management: Applying cultural theory to the history of whaling. Environ. Politics 2016, 25, 414-422. [CrossRef]

49. Yazdanpanah, M.; Hayati, D.; Thompson, M.; Yamani, G.; Monfarad, N. Policy and plural responsiveness: Taking constructive account of the ways in which iranian farmers think about and behave in relation to water. Hydrology 2014, 514, 347-357. [CrossRef]

(C) 2017 by the authors. Licensee MDPI, Basel, Switzerland. This article is an open access article distributed under the terms and conditions of the Creative Commons Attribution (CC BY) license (http://creativecommons.org/licenses/by/4.0/). 